\title{
Brain-to-Brain Neural Synchrony During Social Interactions: A Systematic Review on Hyperscanning Studies
}

\author{
Chang S. Nam ${ }^{1, *(\mathbb{D}}$, Sanghyun Choo ${ }^{1} \mathbb{D}$, Jiali Huang ${ }^{1}(\mathbb{D})$ and Jiyoung Park ${ }^{2} \mathbb{D}$ \\ 1 Fitts Department of Industrial and Systems Engineering, North Carolina State University, \\ Raleigh, NC 27695, USA; schoo2@ncsu.edu (S.C.); jhuang31@ncsu.edu (J.H.) \\ 2 Department of Clinical Research for Rehabilitation, National Rehabilitation Research Institute, \\ Seoul 01022, Korea; jyparkphd@gmail.com \\ * Correspondence: csnam@ncsu.edu; Tel.: +1-919-515-8140; Fax: +1-919-515-5281
}

Received: 30 July 2020; Accepted: 10 September 2020; Published: 24 September 2020

check for updates

Featured Application: Hyperscanning can be applied to measure and quantify brain activity from two or more people simultaneously, which allows one to assess the neurophysiological basis of human social cognition during social interactions by analyzing the synchronization between multiple brains.

\begin{abstract}
The aim of this study was to conduct a comprehensive review on hyperscanning research (measuring brain activity simultaneously from more than two people interacting) using an explicit systematic method, the preferred reporting items for systematic reviews and meta-analyses (PRISMA). Data were searched from IEEE Xplore, PubMed, Engineering Village, Web of Science and Scopus databases. Inclusion criteria were journal articles written in English from 2000 to 19 June 2019. A total of 126 empirical studies were screened out to address three specific questions regarding the neuroimaging method, the application domain, and the experiment paradigm. Results showed that the most used neuroimaging method with hyperscanning was magnetoencephalography/electroencephalography (MEG/EEG; 47\%), and the least used neuroimaging method was hyper-transcranial Alternating Current Stimulation (tACS) (1\%). Applications in cognition accounted for almost half the studies $(48 \%)$, while educational applications accounted for less than $5 \%$ of the studies. Applications in decision-making tasks were the second most common (26\%), shortly followed by applications in motor synchronization $(23 \%)$. The findings from this systematic review that were based on documented, transparent and reproducible searches should help build cumulative knowledge and guide future research regarding inter-brain neural synchrony during social interactions, that is, hyperscanning research.
\end{abstract}

Keywords: hyperscanning; electroencephalography (EEG); functional magnetic resonance imaging (fMRI); functional near-infrared spectroscopy (fNIRS); magnetoencephalography (MEG)

\section{Introduction}

The research on the dynamics of human brain activity has largely taken one of the three main approaches. The first approach comprises the classic cognitive neuroscience paradigm, i.e., the measurement of intra-personal (within-person) brain activity, with a focus on the functional specialization of the individual brain as well as its activity in creating representations of the inner and outer world [1]. The second approach emerged from the field of social neuroscience as a 'multi-level analysis of social psychological phenomena' that investigates intra-personal brain dynamics during inter-personal interactions [2]. A new, third approach has recently been emerging 
whereby brain activity from two or more people can be measured and quantified simultaneously during a particular motor or cognitive task [3,4]. Studying the so-called 'social brain,' which allows us to interact with other people [5], has been one of the fastest growing and most challenging issues in neuroscience [6]. However, since the introduction of the simultaneous recording of the cerebral activity from different subjects using various neuroimaging methods such as electroencephalography (EEG) [7], functional magnetic resonance imaging (fMRI) [8], functional near-infrared spectroscopy (fNIRS) [9] and magnetoencephalography (MEG) [10], it has been possible to assess the neurophysiological basis of social behavior by analyzing the synchronization between multiple brains [11,12]. Such approach, whereby brain activity from two or more people can be measured and quantified simultaneously, has been called 'two-person neuroscience' [13], 'inter-personal brain-to-brain coupling' [4], 'dynamical coupling' [14], 'entrainment' [15], or collectively 'hyperscanning' [16].

Figure 1 shows a timeline of major events in hyperscanning research. Montague et al. [8] first coined the term 'hyperscanning' in a proposal which described both the hardware and software necessary to make simultaneous fMRI recordings of two people playing a game. King-Casas et al. [17] were the first to used fMRI to measure brain activities and compare the activations in subject pairs. Ahn et al. [18] conducted the first simultaneous EEG/MEG hyperscanning study of inter-brain phase synchronization during social interaction. Recently, Cha and Lee [19] developed a novel approach to quantifying inter-brain synchronization via bispectral analysis.

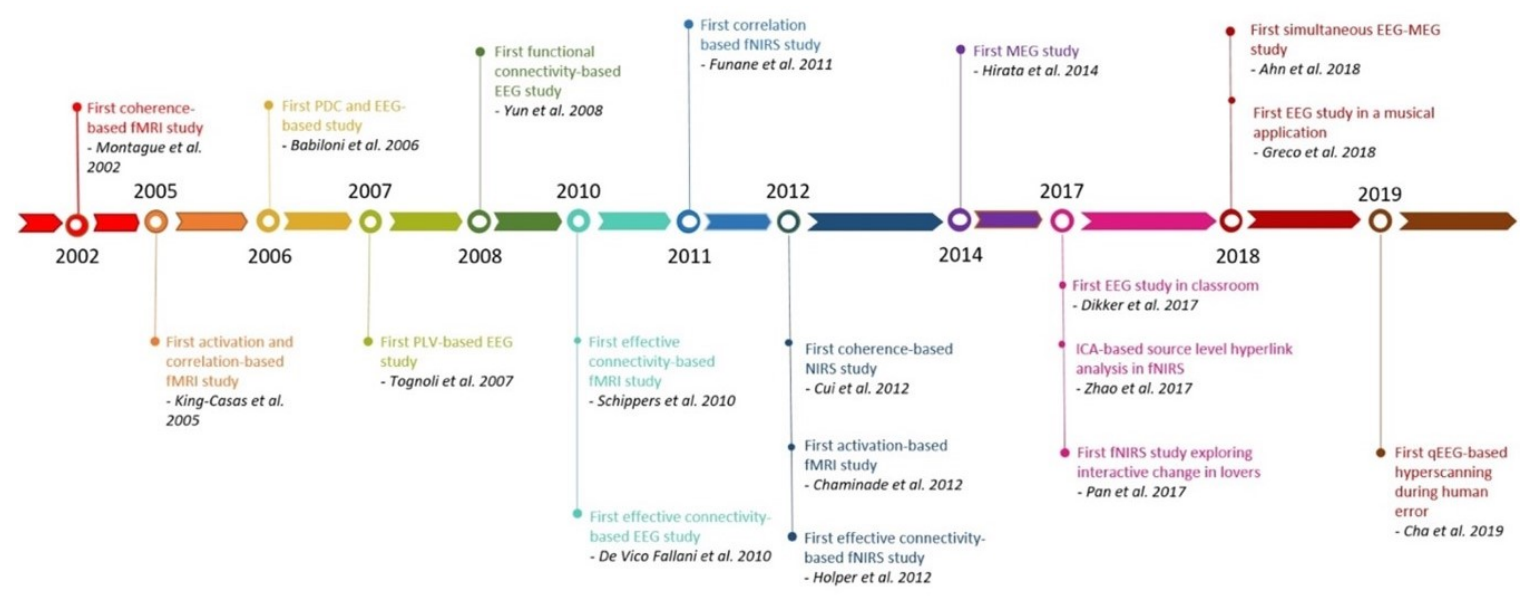

Figure 1. Timelines of hyperscanning advancements.

\subsection{Research Motivation}

Despite its relatively short history, the field of hyperscanning has made significant progress in the past years on (1) applications, (2) neuroimaging methods, (3) experiment paradigms, and (4) inter-brain synchrony methodologies. First, plenty of successful applications have been demonstrated in many areas, such as common vision [20], temporal motor synchronization [9,21,22], music production [23-25], speech [26,27], shared attention [28], decision-making [3,29,30], classroom learning [31], and cooperative piloting [6]. Second, through technological advancements in neuroimaging methods, NIRS hyperscanning could be conducted using one NIRS scanner to measure simultaneous movements in two subjects [9]. Zhao et al. [32] developed a processing pipeline which incorporated independent component analysis (ICA) as a precursor to calculating hyperconnectivity with fNIRS in source space; previous fNIRS hyperscanning studies had done calculations in sensor space without ICA. Third, recent hyperscanning studies have focused on increasing ecological validity through face-to-face interaction and naturalistic environments [33-36]. In this past year, numerous discoveries have been made including EEG hyperscanning while monitoring in real-time [19] and using fNIRS hyperscanning to simultaneously scan musicians in an ecological setting [37]. Finally, various methods that can quantify inter-brain synchrony have been developed in fNIRS [37], fMRI [38]), MEG [18], and EEG [6] hyperscanning studies. For example, Granger causality was first used in fMRI hyperscanning in 2010 
by Schippers et al. [39]. This effective connectivity measure was first adopted in fNIRS hyperscanning two years later by Holper et al. [40]. Tognoli et al. [41] used Phase Locking Value (PLV) as a functional connectivity measure, in an EEG hyperscanning experiment. In 2008, Yun and colleagues [42] conducted the first functional connectivity-based EEG hyperscanning study with the link patterns of intraand inter-brain.

However, it is also true that contemporary hyperscanning research identifies many gaps in the literature that warrant further investigation. A rapidly-increasing number of published hyperscanning studies occasions various problems, including (i) how to highlight methodological concerns in research studies [43] that can be used to improve future work in the hyperscanning area and (ii) how to identify questions for which the available evidence provides clear answers and thus for which further research is not necessary [44]. Systematic reviews address both of these issues. A systematic review, a "review of the evidence on a clearly formulated question that uses systematic and explicit methods to identify," selects and critically appraises relevant primary research, and extracts and analyzes the data from the studies that are included in the review [45]. However, the literature on hyperscanning has mostly been narratively reviewed, which simply records and assesses the state of knowledge on a particular topic in hyperscanning.

For example, we identified 24 review papers on hyperscanning research published since 2002 (see Table 1). We found these review papers shared a couple of significant limitations in their methods and approaches, which indicates a need for a more systematic review study on hyperscanning. A number of features distinguish our review study from most other review papers. First, in this paper we reviewed state-of-the-art hyperscanning research by neuroimaging methods, research paradigms and application types, as well as various methods or indices for quantifying inter-brain synchrony, which other review papers have failed to address specifically. Out of the 24 review papers, two review papers $[46,47]$ gave a general timeline of hyperscanning research but failed to dive into the research paradigms and indices in hyperscanning. Six papers discussed one methodology [48-53] and four papers reviewed multiple modalities [12,54-56]. The applications discussed were joint action [57,58], social neuroscience $[59,60]$, social interaction $[13,61-64]$, and interpersonal coordination $[65,66]$. Finally, this review draws its conclusions from the empirical data collected from hyperscanning experimental studies. Our review is unique in that it examines neuroimaging methods e.g., [48,52,54,67], research paradigms, and application domains e.g., $[57,68]$ for future hyperscanning research.

Table 1. A summary of 24 review papers on hyperscanning research published since 2002.

\begin{tabular}{|c|c|c|}
\hline & Catagory & Studies \\
\hline \multirow{4}{*}{ Modality } & fMRI family & {$[48]$} \\
\hline & fNIRS family & [52] \\
\hline & EEG family & {$[49-51,54,67]$} \\
\hline & Multimodality & {$[12,54-56]$} \\
\hline \multirow{4}{*}{ Application } & Joint action & {$[57,68]$} \\
\hline & Social neuroscience & {$[59,60]$} \\
\hline & Social interaction & {$[11,61-64]$} \\
\hline & Interpersonalcoordination & {$[65,66]$} \\
\hline Other & General hyperscanning & {$[46,47]$} \\
\hline
\end{tabular}

\subsection{Review Objectives}

The overarching objective of this study was to conduct a comprehensive review on hyperscanning research, with the goal of systematically identifying, critically appraising, and synthesizing all relevant studies on inter-brain neural synchrony during social interactions. An explicit systematic method, the preferred reporting items for systematic reviews and meta-analyses (PRISMA) was used to address 
three specific research questions (RQs) regarding the neuroimaging method (RQ1), the application domain (RQ2), the and experiment paradigm (RQ3), which articulate the current-state-of research being conducted with hyperscanning. PRISMA is known to minimize bias and thus provide reliable findings from which conclusions can be drawn [69]. To the best of our knowledge, this is the first systematic review study that used PRISMA to compile all relevant and cutting-edge hyperscanning research to address the current state-of-the-art hyperscanning research since the first publication in 2002.

RQ1. What is the frequency of the four major neuroimaging methods being used in hyperscanning studies? To answer RQ1, this paper calculated the frequency of research conducted by different neuro-imaging methods being used in the selected 126 hyperscanning studies. To effectively organize and draw data from these papers, we first sorted them by the four major neuroimaging methods: magnetoencephalography (MEG) and electroencephalography (EEG); near-infrared spectroscopy (NIRS) and functional near-infrared spectroscopy (fNIRS); magnetic resonance imaging (MRI) and functional magnetic resonance imaging (fMRI); and others. It is important to know which neuroimaging methods are most frequently used, because that information can show us which hyperscanning methodologies researchers should focus on improving first to further neural synchrony research.

RQ2. In what areas has past and current hyperscanning research been conducted within each neuroimaging method? To address RQ2, this paper further categorized the papers in each neuroimaging method by application domain (e.g., cognition, decision-making, motor synchronization, and education) to report the number of studies performed in each application.

RQ3. How have past and current hyperscanning research studies been experimentally designed within each neuroimaging method and application area? To address RQ3, this paper looked into the frequency of different experimental methods (setting, orientation, and group size) within each application. This information is able to tell us what current research is using for hyperscanning experiments and how that changes based on application. From here, we are able to discuss why certain applications prefer one neuroimaging method, setting, orientation, or group size over another, and whether research should be conducted using other experimental methods to advance research in that application.

\section{Review Method}

A systematical approach, PRISMA [69], was utilized in this review. Research articles were sought out from five major search engines: (a) IEEE Xplore, to provide an electrical/electronic engineering perspective; (b) PubMed, to provide a medical perspective, (c) Engineering Village, to provide an engineering perspective; (d) Web of Science, to provide a cross-disciplinary perspective; and (e) Scopus, to provide a broad-spectrum perspective $[70,71]$.

\subsection{Inclusion and Prescreening Criteria}

Inclusion criteria were journal articles written in English from 2000 to 19 June 2019, since the first journal article related to hyperscanning research was published in 2002 [8]. Other publication forms (e.g., proceeding papers, unpublished working papers, master's and doctoral dissertations, newspapers, and books, etc.) were not included. Since journal articles indicate a high level of research, journal articles can help both practitioners and academicians to obtain knowledge and spread their study findings.

Keywords used in search engines were (1) hyperscanning, (2) hyperscanning and inter-brain synchronization or dynamic coupling or brain network or social interaction, (3) hyperscanning or social neuroscience and network index or EEG or MEG or fNIRS or fMRI. Figure 2 shows the flow diagram of PRISMA with the combinations of keywords and the number of studies for each keyword combination from the online databases. After the keyword search, duplicates were removed and 986 articles remained. Those articles were screened again based on titles and abstracts, and 126 research studies remained. 


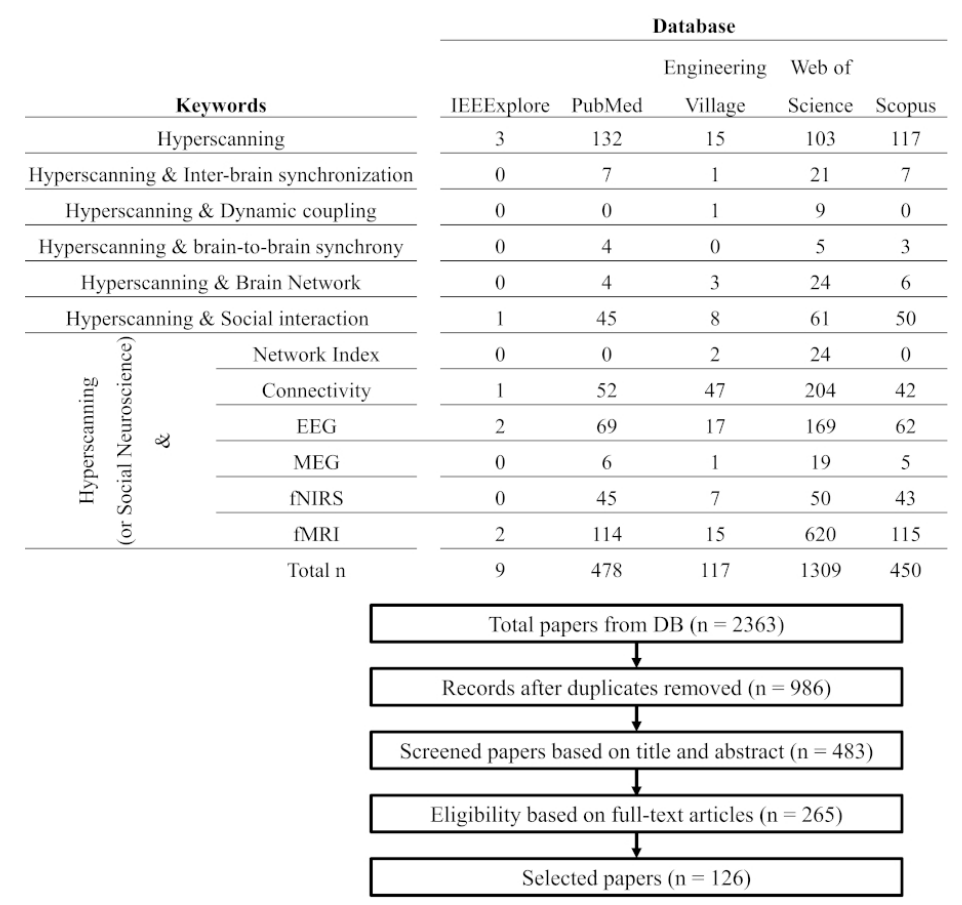

Figure 2. Modified preferred reporting items for systematic reviews and meta-analyses (PRISMA) flow diagram of hyperscanning paper review.

\subsection{Eligibility Criteria}

Prescreened articles were checked for eligibility via full-text screening by following analyses of populations, interventions, comparisons, outcomes, and study design (PICOS) [69]:

Populations: Experiment studies conducted with multiple human subjects for any age, gender, or clinical conditions that meet the inclusion criteria were included. Studies where subjects interacted with each other but their brains were not measured simultaneously were excluded.

Interventions: For RQ1, we screened for studies that used one of the four neuroimaging methods in one of the four application domains. For RQ2, we screened for studies that demonstrated use of a methodology for measuring the inter-brain synchrony between the human subjects.

Comparators: We screened for studies with a design that included a control group or that measured multiple brains so as to provide an inter-brain synchrony comparison.

Outcomes: We screened for studies that accounted for intra-personal brain dynamics during inter-personal interactions using hyperscanning methods.

Study designs: We screened for studies that used one of the three experimental paradigms.

\section{Results and Discussion}

Figure 3 shows the status of hyperscanning based on the 126 selected hyperscanning papers (number of papers, percentage). As shown in Figure 3a, the most used neuroimaging method with hyperscanning was MEG/EEG (60, 47\%) and the least used neuroimaging method was hypertranscranial Alternating Current Stimulation (ACS) (1, 1\%). fNIRS/NIRS hyperscanning was the second most used neuroimaging method $(44,35 \%)$, followed by fMRI/MRI hyperscanning $(21,17 \%)$. Figure $3 \mathrm{~b}$ shows the frequencies of the research applications across the 126 selected papers. Applications in cognition accounted for almost half the studies $(60,48 \%)$, while educational applications accounted for less than $5 \%$ of the studies $(4,3 \%)$. Applications in decision-making tasks were the second most common $(33,26 \%)$, shortly followed by applications in motor synchronization $(29,23 \%)$. 


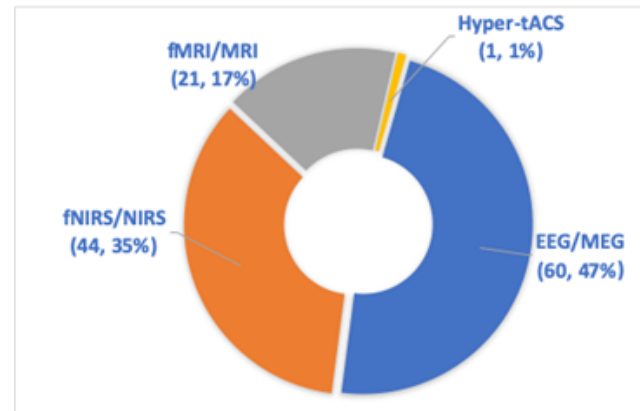

(a) Neuroimaging methods

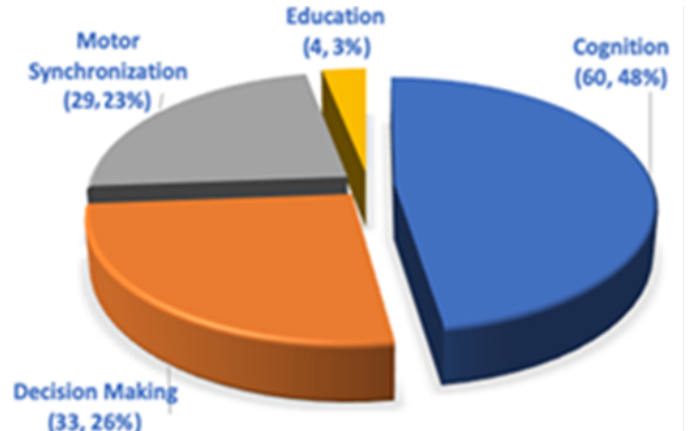

(b) Applications

Figure 3. Current state of the art of hyperscanning research. The two numerical values in the parenthesis indicate that, out of the 126 selected hyperscanning papers, the number of hyperscanning studies that used (a) each neuroimaging method (e.g., $21 \mathrm{fMRI} / \mathrm{MRI}$ papers) and its percentage (e.g., 21/126 = 17\%), and that were conducted in (b) each application domain (e.g., 29 motor synchronization) and its percentage (e.g., 29/126 $=23 \%$ ).

\subsection{MEG/EEG-Based Hyperscanning Research}

Table 2 shows a summary of 60 MEG/EEG-based hyperscanning papers. Of 60 MEG/EEG-based hyperscanning papers, the cognition category was the most common application $(28,47 \%)$, followed by decision-making $(16,27 \%)$, motor synchronization $(14,23 \%)$ and education $(2,3 \%)$. Out of the hyperscanning studies performed with MEG/EEG, 83\% (50/60) of the studies were performed in a laboratory setting. As far as participant orientation and organization, 57\% (34/60) of the studies were performed with participants in a face-to-face orientation, and $83 \%(50 / 60)$ were performed with participants in pairs.

\subsubsection{Cognition}

The cognition application makes up 47\% (28/60) of the research done with the MEG/EEG neuro-imaging methodology. The majority of studies were done by giving participants a visual, auditory, or speech task. Computer games were used to investigate the cognition applications [57,72-74]. Another task was facial expression or visual search activity [19,75-77]. For example, Lachat [78] did the first study to associate joint attention with alpha and mu rhythm modulations and used an eye-gaze task. Some studies used listen/response activities [27,79-81]. Perez et al. [80] investigated interbrain synchronization patterns in pairs of participants interacting through speech by having participants alternate between the role of speaker/listener for semi-structured oral narratives without interpersonal visual contact. Some studies utilized in-person games or role-play [34,82-84]. Venturella et al. [82] looked at how hyperscanning can be used in leadership/management of a business. This study had participants role-play as a leader and an employee during a work performance evaluation. This role-play showed information about leadership and communicative styles. Six studies looked at the neural-synchrony between musicians during a performance. Three of the studies looked at musicians who played guitar $[25,85,86]$, and three other studies looked at musicians who played the saxophone $[23,87,88]$. One unique study was the first to look at the effect of physical touch (handholding) on pain alleviation [89]. Using couples that were either married or strangers, the study found that hand-holding during pain increases the neural synchrony between pairs and improves the accuracy of observer's empathic reaction based on how accurately the second participant rated his partner's pain level.

Setting. A majority of studies (25/28, 89\%) were conducted in the lab while $11 \%(3 / 28)$ of the studies were done in a natural setting $[23,87,90]$. For example, Babiloni et al. [87] demonstrated that the EEG methodology is suitable for high-quality EEG data in subjects playing in an ensemble outside of a lab. Recently, Fenwick et al. [90] was the first study to investigate neural synchrony during meditation. 
In this experiment, a 60-year old French philosopher and meditation teacher led a meditation practice (without verbal communication) for himself and two male pupils in a natural meditation setting.

Orientation. Of the 28 studies in the cognition application, $61 \%(17 / 28)$ were done with participants seated side-by-side, while 39\% (11/28) were done with participants seated face-to-face. Studies on musicians were arranged side-by-side as they were recorded with EEG while playing their instrument $[23,25,87,91]$. Recently, Cha et al. [19] had pairs of male subjects look for the wrong pieces of a puzzle in order to quantify the neural synchrony between subjects during a collaborative process through EEG hyperscanning.

Group Size. Eighteen percent (5/28) of the studies looked at the neural responses in more than two participants compared to pairs [23,75,87,88,91]. For example, Greco et al. [88] was the first study on neural synchrony between musicians. This study evaluated the eventual occurrence of synchronous oscillatory brain activity across subjects through an EEG hyperconnectivity study done with a professional quartet. Muller et al. [91] explored the role of interbrain synchronization based on brain network indices (e.g., small-worldness, efficiency) when playing in music in an ensemble. Burgess et al. [75] aimed to compare the performance of different hyper-connectivity measures using simulated data and individually recorded EEG hyperscanning.

\subsubsection{Decision-Making Task}

The decision-making task application makes up 27\% (16/60) of the research done with the MEG/EEG neuro-imaging methodology $[3,6,16,29,36,42,92-101]$. The goal of these studies was to see the neural-synchrony between participants as they either collaborated and made decisions (trust/cooperative) or made secret decisions (deception/competitive). These experiments most frequently used the prisoner's dilemma game and/or a card game to test participants ability to decide under different conditions. Four studies looked at decision-making between pilots and co-pilots in a flight simulator $[6,16,92,98]$. One study used a version of the ultimatum game to study decision-making [42], while one other study used a cooperation/competitive game [99].

Setting. Most of the studies $(75 \%, 12 / 16)$ were done in the lab, while the rest were done in a natural setting. For example, Astolfi et al. [95] used the Prisoner's Dilemma Game, which has the players choose to either cooperate or defect, to understand the cerebral processes generating and generated by social cooperation or competition. Toppi et al. [6] used the pilot flight simulator to investigate brain-to-brain synchrony of cooperative behavior in ecological settings.

Orientation. Half of the studies (9/18) were done with participants facing each other. For example, Babiloni et al. [94] was the first study to use EEG hyperscanning and PDC for brain network. This study investigated the links between prefrontal areas of the different subjects while they played a card game. Two research papers in this application performed two different experiments with different participant orientations and a different number of participants. The first study [100] focused on understanding the cerebral processes generated by social cooperation or competition by doing the following two different experiments: Prisoner's Dilemma Game (pairs seated side-by-side) and a Card game (more than two people seated face-to-face). The second study [3] expanded on the previous study. To account for the different experiments, we counted those two studies twice in the correct category.

Group Size. More than half of the studies $(81 \%, 13 / 16)$ looked at the neural responses in pairs compared to more than two participants (19\%, 3/16). For example, Babiloni et al. [96] focused the concurrent multiple-brains activity depending on cooperation or competition activities during a card game. Astolfi et al. [101] investigated simultaneous multiple-brains activities for cooperation between individuals in the card game domain.

\subsubsection{Motor Synchronization}

The motor synchronization application makes up $23 \%(14 / 60)$ of the research done with the MEG/EEG neuro-imaging methodology [41,58,102-113]. The goal of these studies was to look at how participants are able to coordinate their actions with each other. This was most commonly done by asking participants to perform a motor task such as rhythmically tapping their fingers $[41,104,105]$, 
following someone's lead (imitation) to tap the sensors at the same time $[102,106,108-110]$, or other motor/selective attention tasks $[68,107,111-113]$. Motor synchronization studies were also done via a computer by asking participants to try to coordinate their response times to different matching/shapes games.

Setting. Filho et al. [68] was the only study which explored the shared and complementary mental models in a natural setting. It performed EEG mapping of two brains engaging in the real-world interactive motor task of juggling. The researchers increased difficulty by having participants juggle an increasing number of objects.

Orientation. Less than half the studies, $43 \%$ (6/14), were done with participants facing each other, while $57 \%(8 / 14)$ of the studies employed the side-by-side orientation [102-106,110,112,113]. The studies that were done with participants facing each other used motor synchronization tasks like finger tapping. For example, Naeem et al. [113] investigated sub-band modulations in the mu domain in pairs performing different social coordination tasks-variations of finger tapping and motion imitation. Zhou et al. [108] explored neural signatures of leaders and followers in terms of hand kinematics using dual-MEG.

Group Size. All 14 studies (100\%) looked at the neural responses between pairs of participants, because they all focused on neuro-synchrony and mirror-neuron responses between pairs.

\subsubsection{Education}

These studies were conducted in a classroom setting with portable EEG equipment to measure the brain-to-brain neural synchrony and joint attention between a teacher and her students. The education application makes up 3\% (2/60) of the research done with the MEG/EEG neuro-imaging methodology. The goal of these studies was to gain more knowledge in the learning-process-specifically in a classroom setting. These studies looked into the most effective teaching methods by measuring their neural-responsivity/attention and testing their material retention with quizzes. In the first study done in a classroom application by Dikker et al. [35]. EEG was used to record 12 students' brains simultaneously under different teaching conditions (video vs. lecture) and post-class quizzes were given to measure engagement and material retention. This study showed an increase in students' brain-to-brain synchrony when they are more engaged in class and a positive correlation between brain-to-brain synchrony and teacher likeability. Interestingly, this study also showed that brain-to-brain synchronization was highest in the preferred teaching style (videos), not lectures Bevilacqua et al. [31] extended Dikker et al. [35] research of brain-to-brain synchrony and learning outcomes in a real-world classroom. Specifically, this study evaluated the effect of student-teacher relationships on student-teacher brain-to-brain synchrony in a high school biology class (12th graders). This study found that brain synchrony and quiz scores on class material were higher for educational videos compared to lectures, which is possibly due to videos being more entertaining and therefore more engaging. The study on the biology class found no correlation between student-teacher synchronization and quiz scores, but a positive correlation between student-teacher closeness and quiz scores. However, this study failed to look at retention of information as a function of time and failed to record when, during the class, student-teacher synchrony was highest, and if that timing agrees with the topics covered by missed quiz questions. This information would help to accurately reflect the retention of information.

Setting. No study was done in the lab, instead both studies took place in a natural classroom setting $[31,35]$. During both studies students were able to look at each other and the teacher, thus we classified this as face-to-face orientation.

Orientation. Both studies also evaluated the neural synchrony between the students (group synchrony) and between the student(s) and teacher, thus $100 \%(2 / 2)$ of the studies looked at the neural responses in a classroom of students (more than two participants). This is an effective way to research a classroom setting, because it takes into account student-to-student interaction as a factor. 
Group Size. One study was done over 11 class sessions [35], while the other study took place over six class sessions [31]. Both studies had a sample (class) size of 12 [31,35].

Table 2. Summary of 60 magnetoencephalography/electroencephalography (EEG/MEG)-based hyperscanning studies.

\begin{tabular}{|c|c|c|c|}
\hline Application & \multicolumn{2}{|c|}{ Experiment Paradigm } & Reference \\
\hline \multirow{6}{*}{$\begin{array}{l}\text { Cognition } \\
(28,47 \%)\end{array}$} & \multirow{2}{*}{ Setting } & Lab (25) & {$[10,18,19,25,27,34,57,72-86,88,89,91]$} \\
\hline & & Natural (3) & {$[23,87,90]$} \\
\hline & \multirow{2}{*}{ Orientation } & Face-to-Face (11) & {$[10,27,34,78,79,82,84-86,89,90]$} \\
\hline & & Side-by-Side (17) & {$[18,19,23,25,57,72-77,80,81,83,87,88,91]$} \\
\hline & \multirow{2}{*}{ Group Size } & $\mathrm{n}=2(23)$ & {$[10,18,19,25,27,34,57,72-74,76-86,89,90]$} \\
\hline & & $\mathrm{n}>2(5)$ & {$[23,75,87,88,91]$} \\
\hline \multirow{6}{*}{$\begin{array}{l}\text { Decision- } \\
\text { Making } \\
(16,27 \%)\end{array}$} & \multirow{2}{*}{ Setting } & Lab (12) & {$[16,29,36,42,92-99]$} \\
\hline & & Natural (4) & {$[3,6,100,101]$} \\
\hline & \multirow{2}{*}{ Orientation } & Face-to-Face (9) & {$[3,36,42,93,94,96,99-101]$} \\
\hline & & Side-by-Side (9) & {$[3,6,16,29,92,95,97,98,100]$} \\
\hline & \multirow{2}{*}{ Group Size } & $\mathrm{n}=2(13)$ & {$[3,6,16,29,36,42,93,95-99,101]$} \\
\hline & & $\mathrm{n}>2(5)$ & {$[3,92,94,100,101]$} \\
\hline \multirow{5}{*}{$\begin{array}{l}\text { Motor } \\
\text { Synchronization } \\
(14,23 \%)\end{array}$} & \multirow{2}{*}{ Setting } & Lab (13) & {$[41,102-113]$} \\
\hline & & Natural (1) & {$[58]$} \\
\hline & \multirow{2}{*}{ Orientation } & Face-to-Face (6) & {$[41,68,105,108,112,113]$} \\
\hline & & Side-by-Side (8) & {$[102-104,106,107,109-111]$} \\
\hline & Group Size & $\mathrm{n}=2(14)$ & {$[41,68,102-113]$} \\
\hline \multirow{3}{*}{$\begin{array}{l}\text { Education } \\
(2,3 \%)\end{array}$} & Setting & Natural (2) & {$[31,35]$} \\
\hline & Orientation & Face-to-Face (2) & {$[31,35]$} \\
\hline & Group Size & $\mathrm{n}>2(2)$ & {$[31,35]$} \\
\hline
\end{tabular}

\subsection{NIRS/fNIRS-Based Hyperscanning Research}

NIRS and fNIRS hyperscanning are common methodologies for experimental studies, given their increased ecological validity compared to other neuro-imaging methods. While NIRS has a lower temporal resolution compared to EEG, it has a significantly higher spatial resolution [114]. Table 3 shows a summary of 44 NIRS/fNIRS-based hyperscanning papers. The most common application is cognition, representing seventeen of the 44 studies (38.6\%). Studies with decision-making task applications comprised thirteen of the 44 studies $(29.5 \%)$, closely followed by applications in motor synchronization, composed of twelve studies (27.3\%). Applications in education were the least common, with only two studies (4.6\%). Some examples of fNIRS/NIRS hyperscanning experimental tasks include computer games, motor tasks, synchronization games, musical activities, and facilitated discussion/brainstorming sessions.

\subsubsection{Cognition}

NIRS and fNIRS hyperscanning have been used for cognitive applications in numerous experimental tasks. These experimental tasks include computer games [114-118], verbal communication [26,119,120], music [37,116,121], gift exchange [122], photography [123], singing [124], the Prisoner's Dilemma Game [125,126], and puzzles [127]. Using cooperative and competitive computer games, Reindl et al. [117] examined the neurobiological underpinnings of emotional bond formation and a child's development of emotional regulation. Furthermore, given the increased prevalence of virtual communication, another study [26] investigated the neural difference between face-to-face communication and other forms of communication, such as through a computer. For example, the most recent fNIRS hyperscanning 
study for applications in cognition explored the effect of prosocial behavior through all-female pairs engaging in a gift exchange task [122]. The results showed that a greater interpersonal engagement between two individuals can lead to significant increase in the coordination of behavioral activities.

Setting. Out of the seventeen studies, two were conducted in a natural setting [37,120], while the majority (15) were conducted in a lab setting. For example, Reindl et al. [117] tested the coherence between parents and children pairs while they played a cooperation-or-competition game in the lab.

Orientation. Eight studies oriented participants side-by-side [37,114-117,121,122] while nine studies had participants face each other $[26,116,118-120,123,124,126,127]$ to complete experimental tasks.

Group Size. Three studies had participant group sizes greater than two [119,120,127], but a majority (13) organized participants into pairs. Some studies only selected male participants [114,118,121], others selected only female participants [116,122], and the remaining studies included both male and female participants.

\subsubsection{Decision-Making Task}

NIRS and fNIRS hyperscanning has been used in a variety of decision-making task applications, particularly forms of cooperative and competitive games. Common experimental tasks include computer games [9,128-131], card games [33,132], an economic exchange game [30], creative thinking [133,134], and cooperative tasks $[135,136]$. A unique experimental task incorporated the game of Jenga [130].

Setting. Out of the thirteen studies, two were conducted in a natural setting $[9,130]$, while the majority were conducted in a lab setting.

Orientation. Five studies oriented participants side-by-side $[9,128-131,134]$, while eight studies had participants sit face-to-face $[30,33,130-133,135,136]$.

Group Size. The majority (12) organized participants into pairs as in the cognition application e.g., [137], while two studies organized participants in groups greater than two [135,136,138].

Only one study selected all female participants [135], while the remaining incorporated both male and female subjects in the studies. A study with a large sample size ( $\mathrm{n}=222,112$ males) sought to understand how cooperation is influenced by male-male, female-female, and male-female pairings [131]. For example, the most recent fNIRS hyperscanning study which focused on decision-making tasks investigated how different feedback affects group creative performance to reveal the underlying interpersonal neural correlates [134]. The experiment consisted of a group brainstorming and feedback session with a large sample size $(n=118,16$ males $)$.

\subsubsection{Motor Synchronization}

Applications in motor synchronization were relatively common and generally had participants complete synchronous physical motions as an experimental task in the lab e.g., [139]. These tasks included a cooperative button press task [140] where participants interact either side-by-side e.g., [141] or face-to-face e.g., [142], computer games [51,141-143], joint-tapping tasks [32,40,144], and synchronization tasks [145-147]. One study utilized a finger-tapping task to record between-brain hemodynamics [40]. A unique study examined cooperation-related inter-brain synchrony between mothers and their children [147].

Setting. All of the twelve studies in applications in motor synchronization were conducted in a lab setting such as in [32,41,139]. For example, Funane et al. [140] tested the correlation between fNIRS signals and time intervals of button pressing after hearing auditory cues. They were able to manipulate the auditory stimulations and sync with the fNIRS equipment in a lab setting.

Orientation. Applications in motor synchronization adopted various orientation methods e.g., [32,40,51,139-147]. For example, Six studies had participants oriented side-by-side [51,139,141-143,146], Two studies had participants oriented back-to-back [32,144], and four of the studies had participants interact face-to-face $[40,140,145,147]$. 
Group Size. One group organized participants into groups greater than two [139], but the majority (11) organized participants into pairs. One study selected only females for a coordination task [145], while the remaining studies incorporated both males and females.

\subsubsection{Education}

Applications in education were the least common among NIRS and fNIRS hyperscanning studies, with only two studies investigating education. First, Brockington et al. [148] utilized fNIRS hyperscanning to explore different paradigms between teachers and students in an academic context. The study conducted three small experiments, two in a classroom and one featuring a single student with eye-tracking glasses.

The results provide proofs of concept for the application of near-infrared spectroscopy in scenarios that more closely resemble authentic classroom routines and daily activities [148]. Recently, fNIRS hyperscanning has expanded its application in education by investigating how communication mode and knowledge state impacted teaching effectiveness [149]. The results found that higher task-related interpersonal neural synchronization (INS) in the left prefrontal cortex (PFC) was found in the FTF teaching condition with prior knowledge. The findings suggest that INS could be a possible neuromarker for dynamic evaluation of teacher-student interaction and teaching effectiveness. Both studies had experimental tasks where participants role-played in classroom scenarios.

Setting. The two studies were conducted in a classroom-like lab setting $[148,149]$ and had subjects interact face-to-face.

Group Size. One study organized participants in a group larger than two [148], while the other study organized participants into pairs [149].

Table 3. Summary of $44 \mathrm{fNIRS/NIRS-based} \mathrm{hyperscanning} \mathrm{research.}$

\begin{tabular}{|c|c|c|c|}
\hline Application & Experiment & aradigm & Reference \\
\hline \multirow{6}{*}{$\begin{array}{l}\text { Cognition } \\
(17,39 \%)\end{array}$} & \multirow{2}{*}{ Setting } & Lab (15) & {$[26,114,116-119,121-127,137]$} \\
\hline & & Natural (2) & {$[37,120]$} \\
\hline & \multirow{2}{*}{ Orientation } & Face-to-Face (9) & {$[26,117,119,120,123,124,126,127,149]$} \\
\hline & & Side-by-Side (8) & {$[37,114-117,121,122,125]$} \\
\hline & \multirow{2}{*}{ Group Size } & $\mathrm{n}=2(14)$ & {$[26,114,116-118,121-126,137]$} \\
\hline & & $\mathrm{n}>2(3)$ & {$[119,120,127]$} \\
\hline \multirow{6}{*}{$\begin{array}{l}\text { Decision- } \\
\text { Making } \\
(13,30 \%)\end{array}$} & \multirow{2}{*}{ Setting } & Lab (11) & {$[30,33,128-136,138]$} \\
\hline & & Natural (2) & {$[9,130]$} \\
\hline & \multirow{2}{*}{ Orientation } & Face-to-Face (8) & {$[30,33,130-133,135,136]$} \\
\hline & & Side-by-Side (5) & {$[9,128,129,136,138]$} \\
\hline & \multirow{2}{*}{ Group Size } & $\mathrm{n}=2(11)$ & {$[9,30,33,128-133,135,138]$} \\
\hline & & $\mathrm{n}>2(2)$ & {$[134,136]$} \\
\hline \multirow{6}{*}{$\begin{array}{l}\text { Motor } \\
\text { Synchronization } \\
(12,27 \%)\end{array}$} & Setting & Lab (12) & {$[32,40,51,139-147]$} \\
\hline & \multirow{3}{*}{ Orientation } & Face-to-Face (4) & {$[40,140,145,147]$} \\
\hline & & Side-by-Side (6) & {$[51,139,141-143,146]$} \\
\hline & & Back-to-Back (2) & {$[32,144]$} \\
\hline & \multirow{2}{*}{ Group Size } & $\mathrm{n}=2(11)$ & {$[32,40,51,140-147]$} \\
\hline & & $\mathrm{n}>2(1)$ & [139] \\
\hline \multirow{4}{*}{$\begin{array}{l}\text { Education } \\
(2,4 \%)\end{array}$} & Setting & $\mathrm{Lab}(2)$ & {$[148,149]$} \\
\hline & Orientation & Face-to-Face (2) & {$[148,149]$} \\
\hline & \multirow{2}{*}{ Group Size } & $\mathrm{n}=2(1)$ & [149] \\
\hline & & $\mathrm{n}>2(1)$ & [148] \\
\hline
\end{tabular}




\subsection{MRI/fMRI-Based Hyperscanning Research}

MRI/fMRI neuro-imaging hyperscanning studies require each participant to lie completely still in the scanner, yet in order to study social interaction, participants need to interact with each other [55]. Participant interaction in an MRI scanner is performed through a computer interface, which poses questions of real-world validity. Table 4 shows a summary of $21 \mathrm{MRI} / \mathrm{fMRI}$-based hyperscanning papers. Out of the 126 research papers selected for this review study, 21 papers used MRI/fMRI hyperscanning. Figure 3 shows that the cognition category was the most common application addressed with MRI/fMRI $(15,71.4 \%)$, followed by decision-making $(4,19 \%)$ and motor Synchronization $(2,10 \%)$.

Of the hyperscanning studies which used MRI/fMRI, 85.7\% (18/21) of the studies were performed in a laboratory setting. As for participant orientation and organization, 19\% (4/21) of the studies placed participants in a face-to-face orientation and $85.7 \%$ (18/21) put the participants in pairs.

Table 4. Summary of $21 \mathrm{fMRI/MRI-based} \mathrm{hyperscanning} \mathrm{research.}$

\begin{tabular}{|c|c|c|c|}
\hline Application & \multicolumn{2}{|c|}{ Experiment Paradigm } & Reference \\
\hline \multirow{6}{*}{$\begin{array}{l}\text { Cognition } \\
(15,71 \%)\end{array}$} & \multirow{2}{*}{ Setting } & Lab (12) & {$[28,38,39,150,152-159]$} \\
\hline & & Natural (3) & {$[151,160,161]$} \\
\hline & \multirow{2}{*}{ Orientation } & Face-to-Face (3) & {$[154,156,157]$} \\
\hline & & Side-by-Side (12) & {$[28,38,39,150-153,155,158-161]$} \\
\hline & \multirow{2}{*}{ Group Size } & $\mathrm{n}=2(12)$ & {$[28,38,39,150-153,155,158-161]$} \\
\hline & & $\mathrm{n}>2(3)$ & {$[150,160,161]$} \\
\hline \multirow{3}{*}{$\begin{array}{l}\text { Decision- } \\
\text { Making } \\
(4,19 \%)\end{array}$} & Setting & $\mathrm{Lab}(4)$ & {$[8,17,162,163]$} \\
\hline & Orientation & Side-by-Side (4) & {$[8,17,162,163]$} \\
\hline & Group Size & $\mathrm{n}=2(4)$ & {$[8,17,162,163]$} \\
\hline \multirow{4}{*}{$\begin{array}{l}\text { Motor } \\
\text { Synchronization } \\
(2,10 \%)\end{array}$} & Setting & Lab (2) & {$[164,165]$} \\
\hline & \multirow{2}{*}{ Orientation } & Face-to-Face (1) & [164] \\
\hline & & Side-by-Side (1) & [165] \\
\hline & Group Size & $\mathrm{n}=2(2)$ & {$[164,165]$} \\
\hline
\end{tabular}

\subsubsection{Cognition}

The cognition application is the most common area for research when using MRI/fMRI hyperscanning $(15,71.4 \%)$. These studies analyzed neural synchrony between participants who engaged in various activities, with communication, eye contact, and joint attention being common activities of interest. Six studies looked at neural synchrony during communication and speech [38,150-154]. Three studies evaluated neural synchrony in pairs by recording eye-contact [155-157]. One unique study in particular used online video chat between two participants to analyze the neural activity associated with real-time eye contact (in person) versus non-real time eye-contact (video chat). Three studies used computer games to analyze social interaction [28,158,159]. Schippers et al. [39] used charades to map information flow between two brains during gestural (non-verbal) communication. They measured the neural activity between the participant guessing and the participant acting out the word to understand the role of the putative mirror neuron system when not taking part in verbal interactions. Two studies used a movie to measure neural synchrony between subjects while observing social reactions in a movie $[160,161]$.

Setting and Orientation. The most common experimental methods included pairs of participants positioned side-by-side in a lab setting. Twelve of the fifteen experiments done by MRI/fMRI in the cognition category were performed in a lab $(80 \%)$, while the other three studies were done in a natural setting. For example, Jääskeläinen et al. [160] used fMRI to reveal between-subject correlation of fMRI activity in the right hemisphere and frontal cortical areas while watching a movie. During this study, 
participants watched the first $72 \mathrm{~min}$ on an LCD screen with surround sound in a dimly lit room (to simulate a movie theater). Participants were instructed to act as though they were in a movie theater.

The last $36 \mathrm{~min}$ of the movie section was shown to participants during fMRI scanning. In reference to participant orientation, $80 \%$ of the fifteen experiments were done with participants seated side-by-side. For example, Tanabe et al. [156] compared brain activity during eye contact and joint attention between autistic spectrum disorder participants and normal participants. This study was the first to demonstrate neural correlation between individuals with ASD and normal individuals during direct/real-time interaction. The simple idea behind their eye contact/gaze shifting task used the image of balls on a screen to represent where the other participant was looking and had the other participant shift their gaze to where the ball on the screen was. Recently, Koike et al. [157] evaluated the neural activity associated with eye-contact during a mutual interaction. This study used a video capturing and displaying set-up so the participants could look at each other's faces. This study found that mutual interaction during eye contact is mediated by the cerebellum and the limbic mirror system.

Group Size. Looking at the group size in experiments done in the cognition application with MRI/fMRI, $80 \%$ of the fifteen experiments were done with pairs of participants, while the other studies were done with more than two participants in one trial. For example, Wilson et al. [150] used auditory/audiovisual narratives to measure neural synchrony between 24 subjects during the narratives.

\subsubsection{Decision-Making Task}

MRI and fMRI hyperscanning had four studies focusing on applications in decision-making tasks e.g., $[8,17,162,163]$. The first hyperscanning study done was by Montague in 2002 . This study used a competitive two-player computer game to study decision-making during social interactions, and paved the way for future hyperscanning research [8]. King-Casas et al. [17] had participants play an economic trust game to understand social interaction through reciprocity, while another study conducted two experiments using the economic trust game to investigate social credit during a two-person social exchange [163]. The fourth study used an ultimatum game to explore brain processes associated with bidirectional reciprocity [162].

Setting, Orientation, and Group Sizes. All four experiments were conducted in a lab setting, with pairs of participants oriented side-by-side. King-Casas et al. [17] used an economic (trust) game to explore the effect of reciprocity on another person (their partner). This study reports that that reciprocity expressed by one player strongly predicts future trust expressed by their partner-a behavioral finding mirrored by neural responses in the dorsal striatum. Recently, Shaw et al. [162] explored brain processes associated with the bidirectional reciprocity characterizing real-world, repeated dyadic interactions. This study revealed, for the first time, that brain signals implicated in social decision-making are modulated by these estimates of EU, and become correlated more strongly between interacting players who reciprocate one another.

\subsubsection{Motor Synchronization}

MRI and fMRI were the least commonly used methods for investigating motor synchronization. The first study investigated how attention is shared between pairs of subjects [164]. This study conducted three experiments which used an eye blink synchronization experimental task to measure shared attention between a pair of participants. Results from this experiment suggest that shared attention is represented and retained by pair-specific neural synchronization that cannot be reduced to the individual level. The second study [165] evaluated the neural substrates of cooperation using a grip-force synchronization task to evaluate the neural substrates of cooperation during a joint force-production task. Participants were positioned side by side in two separate fMRI machines to measure the neural synchrony while participants attempt to synchronize their grip strength force.

Setting, Orientation and Group Size. Both studies were conducted in a lab setting and organized groups of participants into pairs. Koike et al. [157] evaluated how information is shared and retained between two people by asking participants to interact face-to-face. This study featured an equal number 
of male and female subjects. On the other hand, Abe et al. [165] looked into the neural substrates of cooperation during a joint force-production task, and had participants engage side-by-side. This study only included female subjects.

\section{Conclusions}

We systematically identified, critically appraised, and synthesized 126 relevant studies on inter-brain neural synchrony during social interactions since the first publication in 2002, which fitted the pre-specified eligibility criteria. We used an explicit systematic method, the preferred reporting items for systematic reviews and meta-analyses (PRISMA) to address three specific questions regarding the neuroimaging method (RQ1), the application domain (RQ2), and the experiment paradigm (RQ3).

First, it is important to understand what neuroimaging methods have been frequently used, because that information can show us which hyperscanning methodologies researchers should focus on improving first to further neural synchrony research. To answer RQ1 (What is the frequency of the four major neuroimaging methods being used in hyperscanning studies?), we systematically categorized the selected 126 hyperscanning studies by the four major neuroimaging methods: EEG/MEG, NIRS/fNIRS, MRI/fMRI and hyper-tACS. We found MEG/EEG (47\%) the most widely used neuroimaging method with hyperscanning, and the hyper-tACS method was rarely applied. Second, we further categorized the papers by the application domains of cognition, decision-making, motor synchronization, and education. Applications in cognition accounted for almost half the studies (48\%), while educational applications accounted for less than 5\% of the studies. Applications in decision-making tasks were the second most common $(26 \%)$, shortly followed by applications in motor synchronization (23\%). Finally, we found that hyperscanning research studies have been experimentally designed in various settings, orientations, and group sizes within each neuroimaging method and application area. Measuring brain activity simultaneously from more than two people interacting, or "hyperscanning", has enhanced our understanding of the neurobiological aspects of human social interaction. However, hyperscanning literature has been narratively reviewed in that the reviews have only recorded and assessed the state of knowledge on a particular topic in hyperscanning. PRISMA is known to minimize bias and thus provide reliable findings from which conclusions can be drawn [71].

To the best of our knowledge, this is the first systematic review study that used PRISMA to compile all relevant and cutting-edge hyperscanning research to address the current state-of-the-art hyperscanning research since the first publication in 2002. Future challenges and directions from this review of hyperscanning studies include:

- Various neuroimaging methods (e.g., hyper-tACS) are still required to assess the synchronization between multiple brains.

- The inter-brain synchrony study that compares social interactions between normal individuals and groups with social cognitive impairment would be able to explore research findings on the corresponding brain regions to social cognitive impairment.

- Future studies should pay more attention to more factors that may influence the anatomical and functional similarity of the two brains as well as the inter-brain synchrony.

- Simple and easily interpretable experiment paradigms are still required and need to be extended to a wide range of fields (e.g., natural settings) if this is to be a useful design of social interactive experiments to conduct hyperscanning studies.

This systematic review, based on the findings of documented, transparent, and reproducible searches, should help build cumulative knowledge and guide future research regarding inter-brain neural synchrony during social interactions, that is, hyperscanning research. 
Author Contributions: Conceptualization, C.S.N.; methodology, C.S.N., S.C. and J.H.; validation, C.S.N., S.C. and J.H.; formal analysis, C.S.N., S.C., J.H. and J.P.; investigation, C.S.N., J.H. and J.P.; data curation, C.S.N., J.H. and J.P.; writing-original draft preparation, C.S.N., S.C. and J.H.; writing-review and editing, C.S.N.; visualization, S.C. and J.H.; supervision, C.S.N.; project administration, C.S.N.; funding acquisition, C.S.N. All authors have read and agreed to the published version of the manuscript.

Funding: This research was partly supported by the National Science Foundation (NSF) under Grant NSF BCS-1551688. Any opinions, findings, and conclusions or recommendations expressed in this material are those of the authors and do not necessarily reflect the views of the NSF.

Acknowledgments: We would like to thank all those who have helped in carrying out the research, including Katie Lawson and Erica Zack for her assistance in data collection and initial analysis.

Conflicts of Interest: The authors declare no conflict of interest. The funders had no role in the design of the study; in the collection, analyses, or interpretation of data; in the writing of the manuscript, or in the decision to publish the results.

\section{References}

1. Hasson, U.; Frith, C.D. Mirroring and beyond: Coupled dynamics as a generalized framework for modelling social interactions. Philos. Trans. R. Soc. B Biol. Sci. 2016, 371. [CrossRef] [PubMed]

2. Redcay, E.; Dodell-feder, D.; Pearrow, M.J.; Mavros, P.L.; Gabrieli, J.D.E.; Saxe, R. Live face-to-face interaction during fMRI: A new tool for social cognitive neuroscience. Neuroimage 2010, 50, 1639-1647. [CrossRef] [PubMed]

3. Astolfi, L.; Toppi, J.; Cincotti, F.; Mattia, D.; Salinari, S.; Fallani, F.D.V.; Wilke, C.; Yuan, H.; He, B.; Babiloni, F. Methods for the EEG Hyperscanning. Simultaneous Recordings from Multiple Subjects during Social Interaction. In Proceedings of the 2011 8th International Symposium on Noninvasive Functional Source Imaging of the Brain and Heart and the 2011 8th International Conference on Bioelectromagnetism, Banff, AB, Canada, 13-16 May 2011; pp. 8-11. [CrossRef]

4. Scholkmann, F.; Holper, L.; Wolf, U.; Wolf, M. A new methodical approach in neuroscience: Assessing inter-personal brain coupling using functional near-infrared imaging (fNIRI) hyperscanning. Front. Hum. Neurosci. 2013, 7, 1-6. [CrossRef] [PubMed]

5. Brothers, L.; Ring, B.; Kling, A. Response of neurons in the macaque amygdala to complex social stimuli. Behav. Brain Res. 1990, 41, 199-213. [CrossRef]

6. Toppi, J.; Borghini, G.; Petti, M.; He, E.J.; De Giusti, V.; He, B.; Astolfi, L.; Babiloni, F.; Giusti, V.D. Investigating cooperative behavior in ecological settings: An EEG hyperscanning study. PLoS ONE 2016, 11, e0154236. [CrossRef]

7. Duane, T.D.; Behrendt, T. Extrasensory electroencephalographic induction between identical twins. Science 1965, 150, 367. [CrossRef]

8. Montague, P.R.; Berns, G.S.; Cohen, J.D.; McClure, S.M.; Pagnoni, G.; Dhamala, M.; Wiest, M.C.; Karpov, I.; King, R.D.; Apple, N.; et al. Hyperscanning: Simultaneous fMRI during Linked Social Interactions. Neuroimage 2002, 1164, 1159-1164. [CrossRef]

9. Cui, X.; Bryant, D.M.; Reiss, A.L. NIRS-based hyperscanning reveals increased interpersonal coherence in superior frontal cortex during cooperation. Neuroimage 2012, 59, 2430-2437. [CrossRef] [PubMed]

10. Hirata, M.; Ikeda, T.; Kikuchi, M.; Kimura, T.; Hiraishi, H.; Yoshimura, Y.; Asada, M. Hyperscanning MEG for understanding mother-child cerebral interactions. Front. Hum. Neurosci. 2014, 8, 1-6. [CrossRef] [PubMed]

11. Hari, R.; Henriksson, L.; Malinen, S.; Parkkonen, L. Centrality of Social Interaction in Human Brain Function. Neuron 2015, 88, 181-193. [CrossRef] [PubMed]

12. Babiloni, F.; Astolfi, L. Social neuroscience and hyperscanning techniques: Past, present and future. Neurosci. Biobehav. Rev. 2014, 44, 76-93. [CrossRef] [PubMed]

13. Hari, R.; Kujala, M.V. Brain basis of human social interaction: From concepts to brain imaging. Physiol. Rev. 2009, 89, 453-479. [CrossRef] [PubMed]

14. Chatel-goldman, J.; Congedo, M.; Phlypo, R. Joint BSS as a Natural Analysis Framework for EEG-hyperscanning. In Proceedings of the 2013 IEEE International Conference on Acoustics, Speech and Signal Processing, Vancouver, BC, Canada, 26-31 May 2013. [CrossRef]

15. Jensen, K.M.; Borrie, S.A.; Gillam, R.B. Conversational Alignment: A Study of Neural Coherence and Speech Entrainment; All Graduate Plan B and Other Reports; Utah State University: Logan, UT, USA, 2016. 
16. Astolfi, L.; Toppi, J.; Borghini, G.; Vecchiato, G.; Isabella, R.; Fallani, F.D.V.; Cincotti, F.; Salinari, S.; Mattia, D.; He, B.; et al. Study of the Functional Hyperconnectivity between Couples of Pilots during Flight Simulation: An EEG Hyperscanning Study. In Proceedings of the 33rd Annual International Conference of the IEEE EMBS, Boston, MA, USA, 30 August-3 September 2011; pp. 2338-2341. [CrossRef]

17. King-Casas, B.; Tomlin, D.; Anen, C.; Camerer, C.F.; Quartz, S.R.; Montague, P.R. Getting to know you: Reputation and trust in a two-person economic exchange. Science 2005, 308, 78-83. [CrossRef]

18. Ahn, S.; Cho, H.; Kwon, M.; Kim, K.; Kwon, H.; Kim, B.S.; Chang, W.S.; Chang, J.W.; Jun, S.C. Interbrain Phase Synchronization During Turn-Taking Verbal Interaction-A Hyperscanning Study Using Simultaneous EEG/MEG. Hum. Brain Mapp. 2018, 188, 171-188. [CrossRef]

19. Cha, K.M.; Lee, H.C. A novel qEEG measure of teamwork for human error analysis: An EEG hyperscanning study. Nucl. Eng. Technol. 2019, 51, 683-691. [CrossRef]

20. Hasson, U.; Nir, Y.; Levy, I.; Fuhrmann, G.; Malach, R. Intersubject Synchronization of Cortical Activity During Natural Vision. Science 2004, 303, 1634-1640.

21. Hari, R.; Himberg, T.; Nummenmaa, L.; Hämäläinen, M.; Parkkonen, L. Synchrony of brains and bodies during implicit interpersonal interaction. Trends Cogn. Sci. 2013, 17, 105-106. [CrossRef]

22. Konvalinka, I.; Bauer, M.; Stahlhut, C.; Hansen, L.K.; Roepstorff, A.; Frith, C.D. Frontal alpha oscillations distinguish leaders from followers: Multivariate decoding of mutually interacting brains. Neuroimage 2014, 94, 79-88. [CrossRef]

23. Babiloni, C.; Buffo, P.; Vecchio, F.; Marzano, N.; Del Percio, C.; Spada, D.; Rossi, S.; Bruni, I.; Rossini, P.M.; Perani, D. Brains "in concert": Frontal oscillatory alpha rhythms and empathy in professional musicians. Neuroimage 2012, 60, 105-116. [CrossRef]

24. D'Ausilio, A.; Novembre, G.; Fadiga, L.; Keller, P.E. What can music tell us about social interaction? Trends Cogn. Sci. 2015, 19, 111-114. [CrossRef]

25. Lindenberger, U.; Li, S.c.; Gruber, W. Brains swinging in concert: Cortical phase synchronization while playing guitar. BMC Neurosci. 2009, 12, 1-12. [CrossRef] [PubMed]

26. Jiang, J.; Dai, B.; Peng, D.; Zhu, C.; Liu, L.; Lu, C. Neural Synchronization during Face-to-Face Communication. J. Neurosci. 2012, 32, 16064-16069. [CrossRef] [PubMed]

27. Kawasaki, M.; Yamada, Y.; Ushiku, Y.; Miyauchi, E.; Yamaguchi, Y. Inter-brain synchronization during coordination of speech rhythm in human-to-human social interaction. Sci. Rep. 2013, 3, 1-8. [CrossRef] [PubMed]

28. Bilek, E.; Ruf, M.; Schäfer, A.; Akdeniz, C.; Calhoun, V.D.; Schmahl, C.; Demanuele, C.; Tost, H.; Kirsch, P.; Meyer-Lindenberg, A. Information flow between interacting human brains: Identification, validation, and relationship to social expertise. Proc. Natl. Acad. Sci. USA 2015, 112, 5207-5212. [CrossRef] [PubMed]

29. De Vico Fallani, F.; Nicosia, V.; Sinatra, R.; Astolfi, L.; Cincotti, F.; Mattia, D.; Wilke, C.; Doud, A.; Latora, V.; He, B.; et al. Defecting or Not Defecting: How to "Read" Human Behavior during Cooperative Games by EEG Measurements. PLoS ONE 2010, 5, e14187. [CrossRef]

30. Tang, H.; Mai, X.; Wang, S.; Zhu, C.; Krueger, F.; Liu, C.; Mai, X.; Wang, S.; Zhu, C.; Krueger, F.; Liu, C. Interpersonal brain synchronization in the right temporo-parietal junction during face-to-face economic exchange. Soc. Cogn. Affect. Neurosci. Adv. Access 2015, 151, 10-17. [CrossRef]

31. Bevilacqua, D.; Davidesco, I.; Wan, L.; Chaloner, K.; Rowland, J.; Ding, M.; Poeppel, D.; Dikker, S. Brain-to-Brain Synchrony and Learning Outcomes Vary by Student-Teacher Dynamics: Evidence from a Real-world Classroom Electroencephalography Study. J. Cogintive Neurosci. 2018, 26, 1-11. [CrossRef]

32. Zhao, Y.; Dai, R.N.; Xiao, X.; Zhang, Z.; Duan, L.; Li, Z.; Zhu, C.Z. Independent component analysis-based source-level hyperlink analysis for two-person neuroscience studies. J. Biomed. Opt. 2017, 22. [CrossRef]

33. Zhang, M.; Liu, T.; Pelowski, M.; Yu, D. Gender difference in spontaneous deception: A hyperscanning study using functional near-infrared spectroscopy. Sci. Rep. 2017, 7, 7508. [CrossRef]

34. Kinreich, S.; Djalovski, A.; Kraus, L.; Louzoun, Y.; Feldman, R. Brain-to-Brain Synchrony during Naturalistic Social Interactions. Sci. Rep. 2017, 1-12. [CrossRef]

35. Dikker, S.; Wan, L.; Davidesco, I.; Bavel, J.J.V.; Ding, M.; Poeppel, D.; Dikker, S.; Wan, L.; Davidesco, I.; Kaggen, L.; et al. Brain-to-Brain Synchrony Tracks Real-World Report Brain-to-Brain Synchrony Tracks Real-World Dynamic Group Interactions in the Classroom. Curr. Biol. 2017, 27, 1375-1380. [CrossRef] [PubMed] 
36. Jahng, J.; Kralik, J.D.; Hwang, D.u.; Jeong, J. Neural dynamics of two players when using nonverbal cues to gauge intentions to cooperate during the Prisoner' s Dilemma Game. Neuroimage 2017, 157, $263-274$. [CrossRef] [PubMed]

37. Vanzella, P.; Balardin, J.B.; Furucho, R.A.; Morais, G.A.Z.; Janzen, T.B.; Sammler, D.; Sato, J.R. fNIRS responses in professional violinists while playing duets: Evidence for distinct leader and follower roles at the brain level. Front. Psychol. 2019, 10, 1-9. [CrossRef] [PubMed]

38. Spiegelhalder, K.; Ohlendorf, S.; Regen, W.; Feige, B.; van Elst, T.L.; Weiller, C.; Hennig, J.; Berger, M.; Tüscher, O. Interindividual synchronization of brain activity during live verbal communication. Behav. Brain Res. 2014, 258, 75-79. [CrossRef]

39. Schippers, M.B.; Roebroeck, A.; Renken, R.; Nanetti, L.; Keysers, C. Mapping the information flow from one brain to another during gestural communication. Proc. Natl. Acad. Sci. USA 2010, 107, 9388-9393. [CrossRef]

40. Holper, L.; Scholkmann, F.; Wolf, M. Between-brain connectivity during imitation measured by fNIRS. Neuroimage 2012, 63, 212-222. [CrossRef]

41. Tognoli, E.; Lagarde, J.; DeGuzman, G.C.; Kelso, J.A. The phi complex as a neuromarker of human social coordination. Proc. Natl. Acad. Sci. USA 2007, 104, 8190-8195. [CrossRef]

42. Yun, K.; Chung, D.; Jeong, J. Emotional interactions in human decision making using EEG hyperscanning. In Proceedings of the International Conference of Cognitive Science, Seoul, Korea, 27-29 July 2008; p. 4.

43. Eagly, A.H.; Wood, W. Using Research Syntheses to Plan Future Research; Russell Sage Foundation: New York, NY, USA, 1994.

44. Mahood, Q.; Van Eerd, D.; Irvin, E. Searching for grey literature for systematic reviews: Challenges and benefits. Res. Synth. Methods 2014, 5, 221-234. [CrossRef]

45. Jahan, N.; Naveed, S.; Zeshan, M.; Tahir, M.A. How to conduct a systematic review: A narrative literature review. Cureus 2016, 8. [CrossRef]

46. Liu, T.; Pelowski, M. Clarifying the interaction types in two-person neuroscience. Front. Hum. Neurosci. 2014, 8, 1-4. [CrossRef]

47. Liu, T.; Pelowski, M. A new research trend in social neuroscience: Towards an interactive-brain neuroscience. Psych J. 2014, 3, 177-188. [CrossRef] [PubMed]

48. Rettig, S. Quantum Discourse with Hyperscanning and its Potential Implications Quantum Discourse with Hyperscanning and its Potential. J. Soc. Distress Homeless 2008, 0789. [CrossRef]

49. Koike, T.; Tanabe, H.C.; Sadato, N. Hyperscanning neuroimaging technique to reveal the "two-in-one" system in social interactions. Neurosci. Res. 2015, 90, 25-32. [CrossRef] [PubMed]

50. Acquadro, M.A.S.; Congedo, M.; Riddeer, D.D. Music Performance As an Experimental Approach to Hyperscanning Studies. Front. Hum. Neurosci. 2016, 10, 1-13. [CrossRef]

51. Balconi, M.; Vanutelli, M.E. Brains in Competition: Improved Cognitive Performance and Inter-Brain Coupling by Hyperscanning Paradigm with Functional Near-Infrared Spectroscopy. Front. Behav. Neurosci. 2017, 11, 1-10. [CrossRef] [PubMed]

52. Crivelli, D.; Balconi, M. Near-Infrared Spectroscopy Applied to Complex Systems and Human Hyperscanning Networking. Appl. Sci. 2017, 7, 922. [CrossRef]

53. Liu, D.; Liu, S.; Liu, X.; Zhang, C.; Li, A.; Jin, C.; Chen, Y.; Wang, H.; Zhang, X. Interactive Brain Activity: Review and Progress on EEG-Based Hyperscanning in Social Interactions. Front. Psychol. 2018, 9, 1-11. [CrossRef]

54. Czeszumski, A.; Eustergerling, S.; Lang, A.; Menrath, D.; Gerstenberger, M.; Schuberth, S.; Schreiber, F.; Rendon, Z.Z.; König, P. Hyperscanning: A Valid Method to Study Neural Inter-brain Underpinnings of Social Interaction. Front. Hum. Neurosci. 2020, 14, 1-17. [CrossRef]

55. Konvalinka, I.; Roepstorff, A. The two-brain approach: How can mutually interacting brains teach us something about social interaction? Front. Hum. Neurosci. 2012, 6, 1-10. [CrossRef] [PubMed]

56. Wang, M.y.; Luan, P.; Zhang, J.; Xiang, Y.t.; Niu, H.; Yuan, Z. Concurrent mapping of brain activation from multiple subjects during social interaction by hyperscanning: A mini-review. Quant. Imaging Med. Surg. 2018, 8, 819-837. [CrossRef]

57. Sebanz, N.; Knoblich, G.; Prinz, W.; Wascher, E. Twin peaks: An ERP study of action planning and control in coacting individuals. J. Cogn. Neurosci. 2006, 18, 859-870. [CrossRef] [PubMed] 
58. Filho, E.; Bertollo, M.; Tamburro, G.; Schinaia, L.; Chatel-goldman, J.; Di Fronso, S.; Robazza, C.; Comani, S. Hyperbrain features of team mental models within a juggling paradigm: A proof of concept. PeerJ 2016, 4, 1-38. [CrossRef] [PubMed]

59. Dumas, G.; Kelso, J.A.S.; Nadel, J. Tackling the social cognition paradox through multi-scale approaches. Front. Psychol. 2014, 5, 1-4. [CrossRef]

60. Parada, F.J.; Rossi, A. Commentary: Brain-to-Brain Synchrony Tracks Real-World Dynamic Group Interactions in the Classroom and Cognitive Neuroscience: Synchronizing Brains in the Classroom. Front. Hum. Neurosci. 2017, 11, 10-12. [CrossRef]

61. Sänger, J.; Lindenberger, U.; Müller, V. Interactive brains, social minds. Commun. Integr. Biol. 2011, 4, 655-663. [CrossRef]

62. Schoot, L.; Hagoort, P.; Segaert, K. What can we learn from a two-brain approach to verbal interaction? Neurosci. Biobehav. Rev. 2016, 68, 454-459. [CrossRef] [PubMed]

63. Vanutelli, M.E.; Nandrino, J.1.; Balconi, M. The boundaries of cooperation: Sharing and coupling from ethology to neuroscience. Neuropsychol. Trends 2016, 83-104. [CrossRef]

64. Dumas, G.; Lachat, F.; Martinerie, J.; Nadel, J.; George, N. From social behaviour to brain synchronization: Review and perspectives in hyperscanning. IRBM 2011, 32, 48-53. [CrossRef]

65. Cornejo, C.; Cuadros, Z.; Morales, R.; Paredes, J. Interpersonal Coordination: Methods, Achievements, and Challenges. Front. Psychol. 2017, 8, 1-16. [CrossRef]

66. Yan, M.; Cerritos, C.; Khan, F. Neural mechanisms underlying interpersonal coordination: A review of hyperscanning research. Soc. Personal. Psychol. Compass 2018, 12. [CrossRef]

67. Tognoli, E.; Kelso, J.A.S. The coordination dynamics of social neuromarkers. Front. Hum. Neurosci. 2015, 9, 1-16. [CrossRef] [PubMed]

68. Filho, E.; Bertollo, M.; Robazza, C.; Comani, S. The juggling paradigm: A novel social neuroscience approach to identify neuropsychophysiological markers of team mental models. Front. Psychol. 2015, 6, 1-6. [CrossRef]

69. Liberati, A.; Altman, D.G.; Tetzlaff, J.; Mulrow, C.; Gøtzsche, P.C.; Ioannidis, J.P.A.; Clarke, M.; Devereaux, P.J.; Kleijnen, J.; Moher, D. The PRISMA statement for reporting systematic reviews and meta-analyses of studies that evaluate health care interventions: Explanation and elaboration. J. Clin. Epidemiol. 2009, 62, 1-34. [CrossRef]

70. Choi, I.; Rhiu, I.; Lee, Y.; Yun, M.H.; Nam, C.S. A systematic review of hybrid brain-computer interfaces: Taxonomy and usability perspectives. PLoS ONE 2017, 12, e0176674. [CrossRef]

71. Powers, M.B.; Vörding, M.B.Z.V.S.; Emmelkamp, P.M.G. Acceptance and commitment therapy: A meta-analytic review. Psychother. Psychosom. 2009, 78, 73-80. [CrossRef]

72. Astolfi, L.; Toppi, J.; Vogel, P.; Mattia, D.; Babiloni, F.; Ciaramidaro, A.; Siniatchkin, M. Investigating the neural basis of cooperative joint action. An EEG hyperscanning study. In Proceedings of the 2014 36th Annual International Conference of the IEEE Engineering in Medicine and Biology Society, Chicago, IL, USA, 26-30 August 2014; pp. 4896-4899. [CrossRef]

73. Toppi, J.; Ciaramidaro, A.; Vogel, P.; Mattia, D.; Babiloni, F.B.; Astolfi, L.S. Graph Theory in Brain-to-Brain Connectivity: A Simulation Study and an Application to an EEG hyperscanning experiment. In Proceedings of the 2015 37th Annual International Conference of the IEEE Engineering in Medicine and Biology Society (EMBC), Milan, Italy, 25-29 August 2015; pp. 2211-2214. [CrossRef]

74. Balconi, M.; Vanutelli, M.E. Functional EEG connectivity during competition. BMC Neurosci. 2018, 1-11. [CrossRef]

75. Burgess, A.P. On the interpretation of synchronization in EEG hyperscanning studies: A cautionary note. Front. Hum. Neurosci. 2013, 7, 1-17. [CrossRef]

76. Tugin, S.M.; Gorin, A.A.; Kanunikov, I.E.; Shestakova, A.N. Hyperscanning of social attunement: An frn study. Psychol. J. High. Sch. Econ. 2015, 12, 48-63.

77. Szymanski, C.; Pesquita, A.; Brennan, A.A.; Perdikis, D.; Enns, T.; Brick, T.R.; Müller, V.; Lindenberger, U. Teams on the same wavelength perform better: Inter-brain phase synchronization constitutes a neural substrate for social facilitation. Neuroimage 2017, 152, 425-436. [CrossRef]

78. Lachat, F.; Hugueville, L.; Lemaréchal, J.D.; Conty, L.; George, N.; Lemarechal, J.D.; Conty, L.; George, N. Oscillatory brain correlates of live joint attention: A dual-EEG study. Front. Hum. Neurosci. 2012, 6, 1-12. [CrossRef] 
79. Hasegawa, C.; Ikeda, T.; Yoshimura, Y.; Hiraishi, H.; Takahashi, T.; Furutani, N.; Hayashi, N.; Minabe, Y.; Hirata, M.; Asada, M.; et al. Mu rhythm suppression reflects mother-child face-to-face interactions: A pilot study with simultaneous MEG recording. Sci. Rep. 2016, 6, 1-8. [CrossRef] [PubMed]

80. Pérez, A.; Carreiras, M.; Duñabeitia, J.A. Brain-to-brain entrainment: EEG interbrain synchronization while speaking and listening. Sci. Rep. 2017, 7, 1-12. [CrossRef] [PubMed]

81. Pérez, A.; Dumas, G.; Karadag, M.; Duñabeitia, J.A. Differential brain-to-brain entrainment while speaking and listening in native and foreign languages. Cortex 2019, 111, 303-315. [CrossRef] [PubMed]

82. Venturella, I.; Gatti, L.; Vanutelli, M.E.; Balconi, M. When brains dialogue by synchronized or unsynchronized languages. Hyperscanning applications to neuromanagement. Neuropsychol. Trends 2017, 21, 35-52.

83. Ciaramidaro, A.; Toppi, J.; Casper, C.; Freitag, C.M.; Siniatchkin, M.; Astolfi, L. Multiple-Brain Connectivity during Third Party Punishment: An EEG Hyperscanning Study. Sci. Rep. 2018, 8, 1-13. [CrossRef]

84. Zhang, D.; Lin, Y.; Jing, Y.; Feng, C.; Gu, R. The Dynamics of Belief Updating in Human Cooperation: Findings from inter-brain ERP hyperscanning. Neuroimage 2019, 198, 1-12. [CrossRef]

85. Sänger, J.; Müller, V.; Lindenberger, U. Intra- and interbrain synchronization and network properties when playing guitar in duets. Front. Hum. Neurosci. 2012, 6, 1-19. [CrossRef]

86. Sänger, J.; Müller, V.; Lindenberger, U. Directionality in hyperbrain networks discriminates between leaders and followers in guitar duets. Front. Hum. Neurosci. 2013, 7, 1-14. [CrossRef]

87. Babiloni, C.; Vecchio, F.; Infarinato, F.; Buffo, P.; Marzano, N.; Spada, D.; Rossi, S.; Bruni, I.; Rossini, P.M.; Perani, D. Simultaneous recording of electroencephalographic data in musicians playing in ensemble. Cortex 2011, 47, 1082-1090. [CrossRef]

88. Greco, A.; Spada, D.; Rossi, S.; Perani, D.; Valenza, G.; Scilingo, E.P. EEG Hyperconnectivity Study on Saxophone Quartet Playing in Ensemble. In Proceedings of the 2018 40th Annual International Conference of the IEEE Engineering in Medicine and Biology Society (EMBC), Honolulu, HI, USA, 18-21 July 2018; pp. 1015-1018.

89. Goldstein, P.; Weissman-fogel, I.; Dumas, G.; Shamay-tsoory, S.G. Brain-to-brain coupling during handholding is associated with pain reduction. Proc. Natl. Acad. Sci. USA 2018, 115. [CrossRef]

90. Fenwick, P.; Di Bernardi Luft, C.; Ioannides, A.; Bhattacharya, J. Neural correlates of transmitted light experience during meditation: A pilot hyperscanning study. NeuroQuantology 2019, 17, 31-41. [CrossRef]

91. Müller, V.; Sänger, J.; Lindenberger, U. Hyperbrain network properties of guitarists playing in quartet. Ann. N. Y. Acad. Sci. 2018, 1423, 198-210. [CrossRef]

92. Babiloni, F.; Cincotti, F.; Mattia, D.; Mattiocco, M.; Vico Fallani, F.D.; Tocci, A.; Bianchi, L.; Marciani, M.G.; Astolfi, L. Hypermethods for EEG hyperscanning. In Proceedings of the 2006 International Conference of the IEEE Engineering in Medicine and Biology Society, New York, NY, USA, 30 August-3 September 2006; pp. 3666-3669. [CrossRef]

93. Babiloni, F.; Astolfi, L.; Cincotti, F.; Mattia, D.; Tocci, A.; Tarantino, A.; Marciani, M.G.; Salinari, S.; Gao, S.; Fallani, F.D.V.; et al. Cortical Activity and Connectivity of Human Brain during the Prisoner 's Dilemma: An EEG Hyperscanning Study. In Proceedings of the 29th Annual International Conference of the IEEE EMBS, Lyon, France, 22-26 August 2007; pp. 4953-4956.

94. Babiloni, F.; Cincotti, F.; Mattia, D.; Fallani, F.D.V.; Tocci, A.; Bianchi, L.; Salinari, S.; Marciani, M.G.; Colosimo, A.; Astolfi, L. High Resolution EEG Hyperscanning During a Card Game. In Proceedings of the 29th Annual International Conference of the IEEE EMBS, Lyon, France, 22-26 August 2007; pp. 4957-4960.

95. Astolfi, L.; Cincotti, F.; Mattia, D.; De Vico Fallani, F.; Salinari, S.; Marciani, M.; Wilke, C.; Doud, A.; Yuan, H.; $\mathrm{He}$, B.; et al. Estimation of the Cortical Activity from Simultaneous Multi-subject Recordings during the Prisoner's Dilemma. In Proceedings of the 31st Annual International Conference of the IEEE EMBS, Minneapolis, MN, USA, 3-6 September 2009; pp. 1937-1939. [CrossRef]

96. Astolfi, L.; Toppi, J.; Borghini, G.; Vecchiato, G.; He, E.J.; Roy, A.; Cincotti, F.; Salinari, S.; Mattia, D.; He, B.; Babiloni, F. Cortical Activity and Functional Hyperconnectivity by Simultaneous EEG Recordings from Interacting Couples of Professional Pilots. In Proceedings of the 34th Annual International Conference of the IEEE EMBS, San Diego, CA, USA, 28 August-1 September 2012; pp. 4752-4755. [CrossRef]

97. Sinha, N.; Maszczyk, T.; Zhang, W.; Tan, J.; Dauwels, J.; Zhang, W.; Tan, J.; Dauwels, J. EEG hyperscanning study of inter-brain synchrony during cooperative and competitive interaction. In Proceedings of the 2016 IEEE International Conference on Systems, Man, and Cybernetics (SMC), Budapest, Hungary, 9-12 October 2016; pp. 4813-4818. [CrossRef] 
98. Sciaraffa, N.; Borghini, G.; Aric, P.; Flumeri, G.D.; Colosimo, A.; Bezerianos, A.; Id, N.V.T.; Babiloni, F. Brain Interaction during Cooperation: Evaluating Local Properties of Multiple-Brain Network. Brain Sci. 2017, 7, 90. [CrossRef] [PubMed]

99. Hu, Y.; Pan, Y.; Shi, X.; Cai, Q.; Li, X.; Cheng, X. Inter-brain synchrony and cooperation context in interactive decision making. Biol. Psychol. 2018, 133, 54-62. [CrossRef]

100. Astolfi, L.; Cincotti, F.; Mattia, D.; De Vico Fallani, F.; Salinari, S.; Vecchiato, G.; Toppi, J.; Wilke, C.; Doud, A.; Yuan, H.; et al. Simultaneous estimation of cortical activity during social interactions by using EEG hyperscannings. In Proceedings of the IEEE Engineering in Medicine and Biology Society (EMBC), Buenos Aires, Argentina, 31 August-4 September 2010; pp. 2814-2817. [CrossRef]

101. Astolfi, L.; Toppi, J.; De Vico Fallani, F.; Vecchiato, G.; Salinari, S.; Mattia, D.; Cincotti, F.; Babiloni, F. Neuroelectrical Hyperscanning Measures Simultaneous Brain Activity in Humans. Brain Topogr. 2010, 23, 243-256. [CrossRef] [PubMed]

102. Dumas, G.; Nadel, J.; Soussignan, R.; Martinerie, J.; Garnero, L. Inter-brain synchronization during social interaction. PLoS ONE 2010, 5, e12166. [CrossRef]

103. Dumas, G.; Chavez, M.; Nadel, J.; Martinerie, J. Anatomical Connectivity Influences both Intra- and InterBrain Synchronizations. PLoS ONE 2012, 7, e36414. [CrossRef]

104. Dumas, G.; Martinerie, J.; Soussignan, R.; Nadel, J. Does the brain know who is at the origin of what in an imitative interaction? Front. Hum. Neurosci. 2012, 6, 1-11. [CrossRef]

105. Yun, K.; Watanabe, K.; Shimojo, S. Interpersonal body and neural synchronization as a marker of implicit social interaction. Sci. Rep. 2012, 2, 1-8. [CrossRef]

106. Delaherche, E.; Dumas, G.; Nadel, J.; Chetouani, M. Automatic measure of imitation during social interaction: A behavioral and hyperscanning-EEG benchmark. Pattern Recognit. Lett. 2015, 66, 118-126. [CrossRef]

107. Zhdanov, A.; Nurminen, J.; Baess, P.; Hirvenkari, L.; Jousmaki, V.; Makela, J.P.; Mandel, A.; Meronen, L.; Hari, R.; Parkkonen, L. An Internet-Based Real-Time Audiovisual Link for Dual MEG Recordings. PLoS ONE 2015, 10, e0128485. [CrossRef] [PubMed]

108. Zhou, G.; Bourguignon, M.; Parkkonen, L.; Hari, R. Neural signatures of hand kinematics in leaders vs. followers: A dual-MEG study. Neuroimage 2016, 125, 731-738. [CrossRef]

109. Mu, Y.; Han, S.; Gelfand, M.J. The role of gamma interbrain synchrony in social coordination when humans face territorial threats. Soc. Cogn. Affect. Neurosci. 2017, 1614-1623. [CrossRef] [PubMed]

110. Balconi, M.; Gatti, L.; Elide, M. EEG functional connectivity and brain-to-brain coupling in failing cognitive strategies. Conscious. Cogn. 2018, 60, 86-97. [CrossRef] [PubMed]

111. Balconi, M.; Vanutelli, M.E. EEG hyperscanning and behavioral synchronization during a joint action. Neuropsychol. Trends 2018, 24, 23-48. [CrossRef]

112. Naeem, M.; Prasad, G.; Watson, D.R.; Kelso, J.A.S. Electrophysiological signatures of intentional social coordination in the 10-12 Hz range. Neuroimage 2012, 59, 1795-1803. [CrossRef]

113. Naeem, M.; Prasad, G.; Watson, D.R.; Kelso, J.A.S. Functional dissociation of brain rhythms in social coordination. Clin. Neurophysiol. 2012, 123, 1789-1797. [CrossRef]

114. Liu, T.; Saito, G.; Lin, C.; Saito, H. Inter-brain network underlying turn-based cooperation and competition: A hyperscanning study using near-infrared spectroscopy. Sci. Rep. 2017, 1-12. [CrossRef]

115. Dommer, L.; Jäger, N.; Scholkmann, F.; Wolf, M.; Holper, L. Between-brain coherence during joint n-back task performance: A two-person functional near-infrared spectroscopy study. Behav. Brain Res. 2012, 234, 212-222. [CrossRef]

116. Pan, Y.; Cheng, X.; Zhang, Z.; Li, X.; Hu, Y. Cooperation in Lovers: An fNIRS-Based Hyperscanning Study. Hum. Brain Mapp. 2017, 841, 831-841. [CrossRef]

117. Reindl, V.; Gerloff, C.; Scharke, W.; Konrad, K. Brain-to-brain synchrony in parent-child dyads and the relationship with emotion regulation revealed by fNIRS-based hyperscanning. Neuroimage 2018, 178, 493-502. [CrossRef] [PubMed]

118. Liu, W.; Branigan, H.P.; Zheng, L.; Long, Y.; Bai, X.; Li, K.; Zhao, H.; Zhou, S.; Pickering, M.J.; Lu, C. Shared neural representations of syntax during online dyadic communication. Neuroimage 2019, 198, 63-72. [CrossRef] [PubMed]

119. Jiang, J.; Chen, C.; Dai, B.; Shi, G.; Ding, G.; Liu, L.; Lu, C. Leader emergence through interpersonal neural synchronization. Proc. Natl. Acad. Sci. USA 2015, 112, 4274-4279. [CrossRef] 
120. Nozawa, T.; Sasaki, Y.; Sakaki, K.; Yokoyama, R.; Kawashima, R. Interpersonal frontopolar neural synchronization in group communication: An exploration toward fNIRS hyperscanning of natural interactions. Neuroimage 2016, 133, 484-497. [CrossRef] [PubMed]

121. Koide, T.; Shimada, S. Cheering Enhances Inter-Brain Synchronization Between Sensorimotor Areas of Player and Observer. Jpn Psychol. Assoc. 2018, 60, 265-275. [CrossRef]

122. Balconi, M.; Fronda, G.; Vanutelli, M.E. Donate or receive? Social hyperscanning application with fNIRS. Curr. Psychol. 2019, 38, 991-1002. [CrossRef]

123. Hirsch, J.; Zhang, X.; Noah, J.A.; Ono, Y. Frontal temporal and parietal systems synchronize within and across brains during live eye-to-eye contact. Neuroimage 2017, 157, 314-330. [CrossRef] [PubMed]

124. Osaka, N.; Minamoto, T.; Yaoi, K.; Azuma, M.; Shimada, Y.M.; Osaka, M. How Two Brains Make One Synchronized Mind in the Inferior Frontal Cortex: fNIRS-Based Hyperscanning During Cooperative Singing. Front. Psychol. 2015, 6, 1-11. [CrossRef]

125. Zhang, M.; Ding, K.; Jia, H.; Yu, D. Brain-to-brain synchronization of the expectation of cooperation behavior: A fNIRS hyperscanning study. In Proceedings of the 2018 40th Annual International Conference of the IEEE Engineering in Medicine and Biology Society (EMBC), Honolulu, HI, USA, 18-21 July 2018; pp. 546-549.

126. Zhang, Y.; Meng, T.; Hou, Y.; Pan, Y.; Hu, Y. Interpersonal brain synchronization associated with working alliance during psychological counseling. Psychiatry Res. Neuroimaging 2018, 282, 103-109. [CrossRef]

127. Fishburn, F.A.; Murty, V.P.; Hlutkowsky, C.O.; Caroline, E.; Bemis, L.M.; Murphy, M.E.; Huppert, T.J.; Perlman, S.B. Putting our heads together: Interpersonal neural synchronization as a biological mechanism for shared intentionality. Soc. Cogn. Affect. Neurosci. 2018, 841-849. [CrossRef]

128. Cheng, X.; Li, X.; Hu, Y. Synchronous Brain Activity during Cooperative Exchange Depends on Gender of Partner: A fNIRS-based Hyperscanning Study. Hum. Brain Mapp. 2015, 2048, 2039-2048. [CrossRef] [PubMed]

129. Liu, T.; Saito, H.; Oi, M. Role of the right inferior frontal gyrus in turn-based cooperation and competition: A near-infrared spectroscopy study. Brain Cogn. 2015, 99, 17-23. [CrossRef]

130. Liu, N.; Mok, C.; Witt, E.E.; Pradhan, A.H.; Chen, J.E.; Reiss, A.L. NIRS-Based Hyperscanning Reveals Inter-brain Neural Synchronization during Cooperative Jenga Game with Face-to-Face Communication. Front. Hum. Neurosci. 2016, 10,1-11. [CrossRef]

131. Baker, J.M.; Liu, N.; Cui, X.; Vrticka, P.; Saggar, M.; Hosseini, S.M.H.; Reiss, A.L. Sex differences in neural and behavioral signatures of cooperation revealed by fNIRS hyperscanning. Sci. Rep. 2016, 1-11. [CrossRef] [PubMed]

132. Zhang, M.; Liu, T.; Pelowski, M.; Jia, H.; Yu, D. Social risky decision-making reveals gender differences in the TPJ: A hyperscanning study using functional near-infrared spectroscopy. Brain Cogn. 2017, 119, 54-63. [CrossRef] [PubMed]

133. Xue, H.; Lu, K.; Hao, N. Cooperation makes two less-creative individuals turn into a highly-creative pair. Neuroimage 2018, 172, 527-537. [CrossRef] [PubMed]

134. Lu, K.; Qiao, X.; Hao, N. Praising or keeping silent on partner's ideas: Leading brainstorming in particular ways. Neuropsychologia 2019, 124, 19-30. [CrossRef] [PubMed]

135. Wang, C.; Zhang, T.; Shan, Z.; Liu, J.; Yuan, D.; Li, X. Dynamic interpersonal neural synchronization underlying pain-induced cooperation in females. Hum. Brain Mapp. 2019, 40, 3222-3232. [CrossRef]

136. Lu, K.; Hao, N. When do we fall in neural synchrony with others? Soc. Cogn. Affect. Neurosci. 2019, 14, 253-261. [CrossRef]

137. Pan, Y.; Novembre, G.; Song, B.; Li, X.; Hu, Y. Interpersonal synchronization of inferior frontal cortices tracks social interactive learning of a song. Neuroimage 2018, 183, 280-290. [CrossRef]

138. Liu, T.; Saito, H.; Oi, M. Obstruction increases activation in the right inferior frontal gyrus. Soc. Neurosci. 2015, 0919. [CrossRef]

139. Duan, L.; Dai, R.n.; Xiao, X.; Sun, P.p.; Li, Z.; Zhu, C.Z. Cluster imaging of multi-brain networks (CIMBN): A general framework for hyperscanning and modeling a group of interacting brains. Front. Neurosci. 2015, 9, 1-8. [CrossRef]

140. Funane, T.; Kiguchi, M.; Atsumori, H.; Sato, H.; Kubota, K.; Koizumi, H. Synchronous activity of two people's prefrontal cortices during a cooperative task measured by simultaneous near-infrared spectroscopy. J. Biomed. Opt. 2011, 16. [CrossRef] 
141. Balconi, M.; Vanutelli, M.E. Interbrains cooperation: Hyperscanning and self-perception in joint actions. J. Clin. Exp. Neuropsychol. 2017, 39, 607-620. [CrossRef] [PubMed]

142. Balconi, M.; Pezard, L.; Nandrino, J.1.; Vanutelli, M.E. Two is better than one: The effects of strategic cooperation on intra- and inter-brain connectivity by fNIRS. PLoS ONE 2017, 12, e0187652. [CrossRef]

143. Balconi, M.; Vanutelli, M.E.; Gatti, L. Functional brain connectivity when cooperation fails. Brain Cogn. 2018, 123, 65-73. [CrossRef] [PubMed]

144. Dai, R.; Liu, R.; Liu, T.; Zhang, Z.; Xiao, X.; Sun, P.; Yu, X.; Wang, D.; Zhu, C. Holistic cognitive and neural processes: A fNIRS-hyperscanning study on interpersonal sensorimotor synchronization. Soc. Cogn. Affect. Neurosci. 2018, 13, 1141-1154. [CrossRef]

145. Hu, Y.; Hu, Y.; Li, X.; Pan, Y.; Cheng, X. Brain-to-brain synchronization across two persons predicts mutual prosociality. Soc. Cogn. Affect. Neurosci. 2017, 1835-1844. [CrossRef]

146. Balconi, M.; Gatti, L.; Vanutelli, M.E. When cooperation goes wrong: Brain and behavioural correlates of ineffective joint strategies in dyads. Int. J. Neurosci. 2018, 128, 155-166. [CrossRef]

147. Miller, J.G.; Vrtička, P.; Cui, X.; Shrestha, S.; Hosseini, S.M.; Baker, J.M.; Reiss, A.L. Inter-brain synchrony in mother-child dyads during cooperation: An fNIRS hyperscanning study. Neuropsychologia 2019, 124, 117-124. [CrossRef]

148. Brockington, G.; Balardin, J.B.; Augusto, G.; Morais, Z. From the Laboratory to the Classroom: The Potential of Functional Near-Infrared Spectroscopy in Educational Neuroscience. Front. Psychol. 2018, 9, 1-7. [CrossRef] [PubMed]

149. Liu, J.; Zhang, R.; Geng, B.; Zhang, T.; Yuan, D.; Otani, S.; Li, X. Interplay between prior knowledge and communication mode on teaching effectiveness: Interpersonal neural synchronization as a neural marker. Neuroimage 2019, 193, 93-102. [CrossRef] [PubMed]

150. Wilson, S.M.; Molnar-Szakacs, I.; Iacoboni, M. Beyond superior temporal cortex: Intersubject correlations in narrative speech comprehension. Cereb. Cortex 2008, 18, 230-242. [CrossRef] [PubMed]

151. Stephens, G.J.; Silbert, L.J.; Hasson, U. Speaker-listener neural coupling underlies successful communication. Proc. Natl. Acad. Sci. USA 2010, 107, 14425-14430. [CrossRef]

152. Anders, S.; Heinzle, J.; Weiskopf, N.; Ethofer, T.; Haynes, J.D. Flow of affective information between communicating brains. Neuroimage 2011, 54, 439-446. [CrossRef]

153. Chaminade, T.; Marchant, J.L.; Kilner, J.; Frith, C.D. An fMRI study of joint action-Varying levels of cooperation correlates with activity in control networks. Front. Hum. Neurosci. 2012, 6, 1-11. [CrossRef]

154. Goelman, G.; Dan, R.; Stößel, G.; Tost, H.; Meyer-Lindenberg, A.; Bilek, E. Bidirectional signal exchanges and their mechanisms during joint attention interaction-A hyperscanning fMRI study. Neuroimage 2019, 198, 242-254. [CrossRef]

155. Saito, D.N.; Tanabe, H.C.; Izuma, K.; Hayashi, M.J.; Morito, Y.; Komeda, H.; Uchiyama, H.; Kosaka, H.; Okazawa, H.; Fujibayashi, Y.; et al. Stay tuned: Inter-individual neural synchronization during mutual gaze and joint attention. Front. Integr. Neurosci. 2010, 4, 1-12. [CrossRef]

156. Tanabe, H.C.; Kosaka, H.; Saito, D.N.; Koike, T.; Hayashi, M.J.; Izuma, K.; Komeda, H.; Ishitobi, M.; Omori, M.; Munesue, T.; et al. Hard to "tune in": Neural mechanisms of live face-to-face interaction with high-functioning autistic spectrum disorder. Front. Hum. Neurosci. 2012, 6, 1-15. [CrossRef]

157. Koike, T.; Sumiya, M.; Nakagawa, E.; Okazaki, S.; Sadato, N. What makes eye contact special? Neural substrates of on-line mutual eye-gaze: A hyperscanning fMRI study. eNeuro 2019, 6. [CrossRef]

158. Cacioppo, S.; Zhou, H.; Monteleone, G.; Majka, E.A.; Quinn, K.A.; Ball, A.B.; Norman, G.J.; Semin, G.R.; Cacioppo, J.T. You Are In Sync With Me: Neural Correlates Of Interpersonal Synchrony With A Partner. Neuroscience 2014, 277, 842-858. [CrossRef] [PubMed]

159. Špiláková, B.; Shaw, D.J.; Czekóová, K.; Brázdil, M. Dissecting social interaction: Dual-fMRI reveals patterns of interpersonal brain-behavior relationships that dissociate among dimensions of social exchange. Soc. Cogn. Affect. Neurosci. 2019, 14, 225-235. [CrossRef]

160. Jääskeläinen, I.P.; Koskentalo, K.; Balk, M.H.; Autti, T.; Kauramäki, J.; Pomren, C.; Sams, M. Inter-Subject Synchronization of Prefrontal Cortex Hemodynamic Activity during Natural Viewing. Open Neuroimag. J. 2008, 2, 14-19. [CrossRef] [PubMed]

161. Kauppi, J.P.P.; Jääskeläinen, I.P.; Sams, M.; Tohka, J. Inter-subject correlation of brain hemodynamic responses during watching a movie: Localization in space and frequency. Front. Neuroinform. 2010, 4, 5. [CrossRef] 
162. Shaw, D.J.; Czekóová, K.; Staněk, R.; Mareček, R.; Urbánek, T.; Špalek, J.; Kopečková, L.; Řezáč, J.; Brázdil, M. A dual-fMRI investigation of the iterated Ultimatum Game reveals that reciprocal behaviour is associated with neural alignment. Sci. Rep. 2018, 1-13. [CrossRef] [PubMed]

163. Tomlin, D.; Kayali, M.A.; King-Casas, B.; Anen, C.; Camerer, C.F.; Quartz, S.R.; Read Montague, P. Agent-specific responses in the cingulate cortex during economic exchanges. Science 2006, 312, 1047-1050. [CrossRef] [PubMed]

164. Koike, T.; Tanabe, H.C.; Okazaki, S.; Nakagawa, E.; Sasaki, A.T.; Shimada, K.; Sugawara, S.K.; Takahashi, H.K.; Yoshihara, K.; Bosch-Bayard, J.; et al. Neural substrates of shared attention as social memory: A hyperscanning functional magnetic resonance imaging study. Neuroimage 2016, 125, 401-412. [CrossRef]

165. Abe, M.O.; Koike, T.; Okazaki, S.; Sugawara, S.K.; Takahashi, K.; Watanabe, K.; Sadato, N. Neural correlates of online cooperation during joint force production. Neuroimage 2019, 191, 150-161. [CrossRef]

(C) 2020 by the authors. Licensee MDPI, Basel, Switzerland. This article is an open access article distributed under the terms and conditions of the Creative Commons Attribution (CC BY) license (http://creativecommons.org/licenses/by/4.0/). 